\title{
Promoting intergenerational programmes: where is the evidence to inform policy and practice?
}

\section{Elaine Statham}

This is a post-peer-review, pre-copy edited version of an article published in 'Evidence and Policy'. The definitive publisher-authenticated version: Statham, E., 2009.

Promoting intergenerational programmes: where is the evidence to inform policy and practice? Evidence and Policy: A Journal of Research, Debate and Practice, 5(4), pp.471-488. is available online at: http://www.ingentaconnect.com/content/tpp/ep/2009/00000005/00000004/art00008

UK government and non-governmental organisations are promoting the use of intergenerational programmes in England and Wales to improve community cohesion. However, much thought needs to be given to designing programmes and intergenerational projects stand an increased chance of succeeding if they draw on previous successes and failures. This will only be possible if the dearth of readily accessible and practical information needed by practitioners is rectified. In this article recommendations are made on what needs to be done to progress intergenerational, programmes and relations, achieve successful outcomes and avoid unintended consequences such as reinforcing negative, ageist stereotypes and exacerbating already fragile intergenerational relationships.

\section{Introduction}

The New Labour government has pledged to reduce social exclusion and improve people's social capital. Since the creation of the Department for Communities and Local Government (DCLG), improving community cohesion, although not a new target, has been given a higher profile. This is reflected in the role the Department is taking in the delivery of the Public Service Agreement 21 (PSA 21): build more cohesion, empowered and active communities (DCLG, 2008). Advocates of intergenerational programmes claim that projects that bring together different age groups in collaborative activities help to build both cohesion and social capital. To this end, in a report commissioned by the DCLG, intergenerational programmes are recommended as a vehicle for enhancing community cohesion (CIC, 2007).

While supporting the implementation of intergenerational programmes, this article seeks to demonstrate that much thought needs to be given to designing programmes and that intergenerational projects stand a much better chance of succeeding if they draw on previous successes and failures. Abrams and Giles (1999,p 206) forcefully make the point that:

The design of many intergenerational contact programs occurs without much academic discussion, yet such dialogue is extremely important. Indeed, programs should be designed with a specific purpose(s) in mind that is linked to research and/or evaluation and this does not always appear to be the case.

The practical case study carried out by the author supports this criticism by demonstrating the dearth of readily accessible and practical information that people designing programmes can utilise. Prior to discussing the case study, this article (which focuses on intergenerational relations within communities rather than families) provides an overview of growing interest in intergenerational programmes in both governmental and non-governmental bodies. It then outlines the programmes' theoretical underpinnings, and the aims and types of designs/models used, and this is followed by a discussion of a sample of existing, related research. The article ends with recommendations on what needs to be done to progress further the field of intergenerational programmes and relations. 'What needs to be taken into account to achieve successful outcomes, and how to avoid unintended consequences such as reinforcing negative, ageist stereotypes and exacerbating already fragile intergenerational relationships are also considered. 


\section{Background}

For at least 30 years, particularly in the US, projects bringing together members of different generations have been developed and their effectiveness evaluated and researched. In the UK, interest in intergenerational practice has grown significantly over the last few years, and Centres for Intergenerational Practice in England, Wales and Northern Ireland have been created.' Raynes (200a,p 187) states that 'Intergenerational programmes are beginning to burgeon in England'.

The government is now advocating the use of intergenerational projects to tackle various social problems. HM Treasury and the Department for Children, Schools and Families (DCSF) in its Aiming high for young people: A: ten year strategy for positive outcomes: Implementation plan (HM Treasury and DCSF, 2007) includes reference to intergenerational programmes, and suggests that consideration should be given to how government can 'support more intergenerational activity'. A dedicated government group:

$[\mathrm{H}]$ ave been considering options for embedding intergenerational practice into existing programmes and for promoting the benefits of intergenerational activity, both to our key delivery partners, such as local authorities and third sector organisations, and to the public. (.DCSF,2008, para 5.34)

Victoria Dare, a representative of the DCSF; speaking at a seminar on intergenerational programmes, spoke of the Department's belief that such programmes could be a 'vehicle' for meeting various PSAs (Dare, 2008). In particular, she emphasised the instrumental role of intergenerational programmes in addressing PSA 14: increase the number of children and young people on the path to success; PSA 17: tackle poverty and promote greater independence and wellbeing in later life; PSA 18: promote better health and wellbeing for all; and PSA 21: build more cohesive, empowered and active communities (H M Treasury, 2008). Since then, the DCSF has reinforced its support and commitment by allocating $£ 5.5$ million to fund intergenerational programmes (DCSF,2009).

Of equal significance is the reference made to the value of intergenerational projects in a report produced jointly by HM Treasury and the DCSF. This suggests that involving adult volunteers in youth-related programmes will help adults gain a sense and appreciation of the 'issues and challenges young people face' (HM Treasury and DCSF, 2007 p4l) and, in return, youth will develop an empathy with the needs of others within the community.

The Commission on Integration and Cohesion (CIC) produced a report that included recommendations not only for improving racial and faith-based relations but also intergenerational relations within communities (CIC, 2007). The report cited a comment made by Age Concern, which emphasised the need for intergenerational programmes:

Most recent attention around diversity and community cohesion in the UK has been focused on issues of race and faith, partly owing to recent high profile events...However, the UK is a diverse country, and in many towns and cities intergenerational conflict may be as pressing or a more pressing issue in cohesion and quality of life. (CIC, 2007 p83)

In 2005, a report produced on behalf of the Office of the Deputy Prime Minister (Pain, 2005) highlighted the relevance and potential benefits of employing intergenerational programmes as part of the process of regenerating disadvantaged neighbourhoods.

While the Respect Agenda $^{2}$ launched by the government in 2005 (Respect Task Force, 2006) does not explicitly cite intergenerational programmes as a way of improving mutual respect between community members, it could be argued that it is a useful strategy in achieving this aim. Although it focuses primarily on addressing the disrespectful behaviour of a small minority of young people, there is also a need to address the negative stereotyping of young people by older people. Intergenerational programmes, it is argued by Pain (2005, p20), could be used to good effect in this area. 
Local government departments and agencies are also rising to the challenge of reducing intergenerational conflict, with a number of project models being developed (Lancashire County Council, 2004; West Lindsey District Council, 2004; National Youth Agency, 2008). For example, Darlington District Council (undated) has designed a project in which different age groups work collaboratively to consider 'intergenerational issues, break down barriers, build relationships and raise issues around stereotyping'.

The independent think tank, the Institute for Public Policy Research has produced a report based on research into 'how the experience of youth in Britain has changed and why this has fuelled public disquiet' (Margo et al, 2006, pp vn,f79). It recommends community-based, intergenerational programmes as an effective tool to help socialise young people.

Charitable organisations such as Age Concern and Help the Aged $^{3}$ are also promoting the use of intergenerational programmes. Age Concern has produced a booklet giving examples of 'best practice', promoting the benefits, and explaining the relevance of intergenerational projects to 'current key government priorities' (Berridge, 2006).

\section{Theories underpinning intergenerational Programmes}

Various theories have been advanced to identify the causes of intergenerational conflict or negative attitudes, the major ones being identified by Pinquart et al (2000, pp 525-6) as 'realistic intergroup conflict', 'social identity' and 'deficit of intergenerational contact'.

Conflict or negative attitudes, according to realistic intergroup conflict theory, arise as the result of a 'divergence of goals' between different age groups (Rosenbaum and Button, 1992; Hobman,1993, p8; Walker, 1993,p37; Silverstein et al,2000,pp273-8). The conflict that arises between adolescents and parents as the former want increased independence is one example of this theory (Pinquart et al,2 000,pp 525-6). Another source of conflict can be the perceived inequitable allocation of limited resources such as public sector houses; young families can interpret it as unfair when they are living in 'cramped' conditions while older adults are 'under-occupying' larger, family-sized homes (Tinker, 1993, p65).

Pain (2005) also refers to the conflict that can occur between the young and older generations within communities because the two groups may be in competition for public space. Older people can perceive teenagers' use of public space as a threat to their safety and statistics on fear of crime from the British Crime Survey suggest that a significant number of adults see teenagers 'hanging around' as a very big or fairly big problem (Kershaw et al,2008). Even if the threat is based on negative stereotyping of teenagers rather than personal experience, such perceptions can impact adversely on an individual's quality of life.

Social identity theory argues that the negative attitudes of one group towards another result in intergroup conflict. The 'in-group's' (eg adults') negative attitude towards the 'out-group' (eg adolescents) exists because of the in-group's failure to accept that the 'out-group' is not homogenous; it fails to see or acknowledge that differences exist within the 'out-group'. Equally, because individuals tend to see themselves in a positive light, they naturally attribute the same positive characteristics to the group to which they belong, and attribute negative characteristics to out-groups, resulting in misconstrued stereotyping (Pinquart et al, 2000, p525).

In particular, Caspi (1984, p74) highlights negative stereotyping of older people by children. The term 'ageism', which is now commonly used to describe discriminatory acts against older generations, was first used by Butler in 1969 in connection with 'open conflict between younger and older generations' ( $\mathrm{Ng}, 1998, \mathrm{p105})$. Stereotyping of the older generation is sometimes reinforced by negative images and language in the media. For example, 'wrinkly', a slang word now included in the Concise Oxford Dictionary to describe older adult generations, has negative, offensive connotations (Mayes, 1999). Pain(1997,pp117-18) voices the opinion that academic work also plays a part in reinforcing 'stereotypical and negative images of the ageing process and elderly people's lives 'by not sufficiently exploring issues underlying the concept of ageism. 
However, ageism is not only experienced by older people, and negative stereotyping of teenagers is just as prevalent. Moral panics relating to youth behaviour have a long history; Wyn and White (1997, p21) argue that 'youth as a problem' became a particular issue in the 1950s, reinforced by Rogers $(2004$, p13) who referred to 'a particular boom in adult panics over youth' from the Second World War onwards. Since the advent of 'distinct youth cultures' in the 1950s, teenagers have often been depicted by the media as a threat to society. Such moral panic has been renewed or sustained as each generation of teenagers embraces the youth culture of its times, be it teddy boys in the 1950s, mods and rockers in the 1960s, or hippies, punks, skinheads or ravers in subsequent decades (Furlong and Cartmel, 1997, p60). Today, television often perpetuates the stereotype of youth as surly, uncommunicative and obnoxious. Recent research argues that media coverage has become 'increasingly negative and stereotypical', and some surveys suggest that public opinion favours the notion that young people lack the ability to uphold the norms and values of society (Margo et al, 2006, p14). However, while it may be true that there is a propensity for negative rather than positive press coverage of young people, one comparison of the years 2004-05 shows a reduction in 'negative' stories from $71 \%$ to $57 \%$ (Ipsos M ori, 2006).

Deficit of intergenerational contact theory claims that negative ageist stereotyping and intergenerational conflict result from insufficient social intergroup contact (Pinquart et al,2000, p526), which has been blamed on such factors as the restructuring of the family unit. For example, the divorce of parents and the increase in single-parent families may mean that children have little or no contact with grandparents (Johnson, 1993, p17; Hatton-Yeo and Ohsako,2 000, p 54). Some research suggests however, that this is not the case and that good-quality contact between grandparents and grandchildren still occurs. Chapman and Neal (1990) argue that longer, healthier lifespans mean that young people have contact with grandparents for longer. This may indeed be the case, but there has been no research as yet on whether good quality contact at an interpersonal level between grandparent and grandchild impacts positively on intergenerational contact at an intergroup level. This is of particular importance given the divergence of views on the impact that positive interpersonal contact might have on intergroup relations.

It has been suggested that a growth in age-specific activities (Granville and Ellis, 1999, p233), and the geographical remoteness of older generations from nuclear families, resulting from increased employment-related relocation opportunities (DfEE, 1998, p 2) similarly disconnects the old from the young. The diminution of 'apprenticeships and trade guilds', which in the past were identified as processes through which positive intergenerational relations could develop, has also had an impact on intergenerational contact (Hatton-Yeo and Ohsako,2000,p 5a).

These three theories have dominated discussion of intergenerational conflict in the limited UK-based literature, and they are further described and discussed by Caspi (1984, p74), Hewstone and Brown (1986), Chapman and Neal (1990), Fox and Giles (1993), Tinker (1993, p61), Furlong and Cartmel (1997, p60), Pain (1997, pp117-18), $\mathrm{Ng}$ (1998, p105), Mayes (1999) and Moore and Statham (2006). However, it is worth noting that in her Canadianbased work, Kuehne (2003a) identifies as many as 15 theories that have underpinned intergenerational projects and research.

\section{Programme developments in England and Wales}

From the outset, intergenerational programmes developed in England and Wales have drawn on findings from US studies. For example, if success is to be achieved, programmes should be purposely designed and intended as a continuing process and not just as a by-product of other initiatives. Also, attention needs be given to the detail and clarity of communication between all involved agencies and parties, and intended outcomes should be clearly defined. As facilitators, the middle generation's role is to empower both young and old participants. Equally, for both young and old, programmes should be mutually beneficial and impact positively on their 'quality of life' (Granville and Ellis, 1999, pp235-6). Granville (2002,p 11) writing on behalf of the Centre for Intergenerational Practice, emphasises that, where the project aims to generate reciprocal respect, preparatory work should be carried out with each group to establish their support and understanding of the proposed aim. 


\section{Examples and limitations of US research}

Given the scarcity of UK-based research, this section draws on US-based work for examples of programmes and contributions to gaps in knowledge. Caspi (1984) carried out research to investigate whether contact between young children (aged three to six) and teaching assistants aged $60+$ helped to reduce the negative stereotyping of older people by young children. To test this hypothesis, a project was designed such that one group of children attended a preschool institution where some of the teaching was done by older adults, and another group attended a more 'traditional' preschool setting where older adults were not part of the teaching team. The results did provide evidence that the presence of older teaching assistants and the intergenerational contact this involved had a favourable effect on children's negative stereotyping.

However, as Caspi (1984) acknowledges, there are clear limitations to this work, which prevent any firm conclusions being drawn; in particular, the lack of consideration given to several variables in the data analysis process, including social class and cognitive skills, and the potential variability of 'curriculum content and literary resources available in the participating schools'. The limited age range of the children also raises the question to what extent the findings of this research might be generalisable to, for example, adolescents. In addition, the research was limited to investigating children's attitudes towards older people, and did not seek to investigate changes in older participants' attitudes towards the younger age group.

Chapman and Neal (1990), as a result of scrutinising past intergenerational projects, stated that they had found no 'consistent' evidence that these had improved young people's attitudes towards older adults, nor had they found 'evaluations of programmes focusing on changing the attitudes of the elderly toward adolescents' (1990, p826). As part of their work, Chapman and Neal (1990) carried out research to test the contact model but, unlike Caspi (1984),focused on adolescents rather than young children. The project comprised two elements: one aimed at improving the 'work experience and job skills' of adolescents in which they provided practical help (such as house and garden maintenance) to older adults; and the other involving older adults taking the lead in providing educational and recreational activities for adolescents. Before the project began, the youth group received training on required job skills and the concept of ageing.

Attitudinal data were gathered from the four groups involved (two of older people and two of adolescents), and a perceptible change in attitude was detected in the younger participants engaged in helping older adults. Disappointingly, the authors offer no explanation of why this was the case. Given that Chapman and Neal (1990) also referred to 'educational or training programmes in gerontology' not involving direct intergroup contact that had improved young people's attitudes towards older adults, it is suggested that more research is needed to test the effectiveness of contact and non-contact projects in improving intergenerational relationships.

Fox and Giles (1993) argue that, between the 1970s and 1990s, researchin to the efficacy of intergenerational programmes in reducing negative intergroup stereotyping lacked methodological consistency and theoretical underpinnings, and concentrated on assessing the effects of intergenerational contact on young people to the exclusion of the effects on older adults. They also felt that insufficient consideration had been given to the type and quality of intergenerational communication during projects:

[A] weakness of all intergenerational contact research as well as intergroup contact theory in general, is a failure to look at the actual communicative processes occurring in the contact situation(.Fox and Giles, 1993, p439)

Fox and Giles (1993) argue that the style of communication can have a significant impact on the quality and outcome of interpersonal contact. They refer to communication accommodation theory (CAT), which explains how an individual may need to alter their style of speaking depending on the type of encounter and personal profile of the other party. For example, if an adolescent avoids using teenage slang when talking to an older person, the latter is more likely to understand and there is more likelihood of positive interaction. 
Edwards and Giles (1998) draw attention to CAT, but they also give consideration to the Communication Predicament of Ageing (CPA) Model that has been developed from it. This theory suggests that the quality of interpersonal interaction can be adversely affected if changes to communication style are made to accommodate a perceived need but, in fact, turn out to be unnecessary or patronising (Soliz and Harwood, 2003). For example, a young person speaking loudly because they assume that an older person's hearing is impaired, or an older person speaking in a patronising 'baby-talk' style, may impact negatively on interaction.

Guydkunst (2004) argues that communication between different social groups is often marred because of the anxiety caused by an individual's uncertainty about how the other party might react. He suggests that by equipping individuals with the skills to overcome anxiety and uncertainty communication can be improved and as a result, so can intergroup relations. However, there is limited knowledge about the potential of such projects to break down negative age-specific stereotypes and improve intergenerational communication. To enhance intergenerational relations, research is needed to investigate the potential benefit of projects underpinned by Guydkunst's (2004) anxiety/uncertainty management theory and to establish whether focusing on improving communication techniques to reduce anxiety can reduce intergenerational conflict.

\section{Evaluation of intergenerational programmes}

The implementation of intergenerational programmes as a 'tool' for improving intergenerational relationships and addressing various social issues has been accompanied by a call for greater attention to be paid to rigorous evaluation. Bocian and Newman (1989, pp152-61) set out what they consider to be the strategies and methodologies required to secure knowledge of what makes for effective programmes. For example, evaluation should be 'integral to the programme' and should be undertaken at both the 'formative and summative stages of programme implementation'.

Much of the evaluative work on intergenerational programmes has been carried out in the US and Canada; however, UK-based work is starting to emerge. Although not specifically labelled intergenerational, St James-Roberts and Singh (2001) undertook a three-year evaluation of a project in which adults acted as mentors to school children with the aim of improving their behaviour and educational attainment. However, this evaluation was limited in that it did not address any benefits gained by participating adults, or any resultant change in their attitudes towards young people.

Springate et al (2008) have recently published a much-needed literature review primarily focusing on UK intergenerational projects and, to a lesser extent, drawing on work from abroad. They felt confident that intergenerational projects could make a difference to negative attitudes but also called for more research and project evaluation to test 'the effectiveness of intergenerational practice in a UK context...demonstrating the outcomes from, and key factors of successful projects' (Springate et al, 2008, p18).

\section{The practitioner's perspective}

With a view to developing good practice, Fox and Giles (1993) highlighted three key criteria on which 'theorists and practitioners' should focus:

First, establish realistic goals and expectations as well as supportive augmenting factors attending to the prevailing norms and features of the wider social milieu. Second. Ensure that contact encounters are seen as intergroup ones that involve appropriate prototypically-perceived others. Third, promote mutually-attuned communicative strategies that will be interpreted by recipients positively as such and will lead to favourable communicative outcomes likely to facilitate further contact.(Fox andGiles, 1993 pp446-7)

This is sensible and practical advice, and one might expect that in the 16 years since it was published, a significant amount of more detailed, practical guidance on how to achieve these aims would have become available. In fact, the amount of literature available, in particular guidelines for practitioners, is relatively disappointing. 
To investigate the extent to which research and evaluation findings, and practical guidance, are available and comprehensible to practitioners, I undertook a limited search for publications; the aim being to replicate the kind of search that might be conducted by a practitioner tasked with developing a community-based intergenerational project, who had no previous knowledge in this field, limited time and limited knowledge of and skills in searching appropriate information resources. The search term 'setting up intergenerational projects', the search engine most likely to be used (Google) and the time to be devoted to this exercise were determined following discussion with a group of practitioners. Using these assumptions, two hours were spent searching Google and the websites of three IJK government departments: the Department for Education and Skills ${ }^{4}$ (DfES), DCLG and DCSF.

The government websites produced little useful information. The DfES website recommended a document aimed at teachers delivering the citizenship curriculum, and the DCLG and DCSF revealed one and nil documents respectively. Using the term 'intergenerational', one document was found on the DCLG website but none on the DCSF website.

The search carried out on Google revealed 289,000 links, but on the basis that practitioners have limited time to trawl through the results, I spent one hour searching for documents I considered worth exploring further. This exercise resulted in the exploration of six links, two of which featured the same intergenerational project. While the information contained in the documents accessed was interesting and gave ideas for project design, it was limited in detail; although one document did provide a useful list of websites and links to additional information.

Following these disappointing results, it was decided to run another exercise based on the assumption that the practitioner had acquired the work of Springate et al (2008) and could spend time accessing the content of the reference list for project design guidance. The Springate et al (2008) review was based on intergenerational practice literature produced since 2002 in the UK or abroad, totalling 32 and 11 documents respectively. These included research studies, project evaluations, discussion papers, reports, literature review/review evidence and practical guides. Although Springate et al (2008) only reviewed 43 of the 47 documents found, for the purposes of this exercise I undertook a search for all 47.

Through systematically working through the references, I discovered that only 15 of the 47 were freely accessible, while a further five were available via a journal subscription. However, none of the 15 accessed was revealed during the Google search referred to earlier. Therefore, a practitioner would have to be aware of the Springate et al document's existence to have easy access to a limited number of resources or, assuming that a more thorough trawl of Google would provide electronic links, a practitioner would need to have a considerable amount of time available to spend on pre-project research. It seems unlikely that a practitioner would have the time or commitment to access, evaluate and draw useful conclusions from these information sources.

The results of this exercise were disappointing, although - given the tenor of Greenwood and Levin's (2008) criticism of academics writing for academics- not entirely surprising. The author is aware that the Centre for Intergenerational Practice (CIP) produces guidelines for projects, but the internet search carried out within the parameters set for the exercise did not bring up the Centre for Intergenerational Practice's website or its publications, so a practitioner would not become aware of it.

The report commissioned by the DCLG and identified by the Google search promotes intergenerational programmes as a way of improving community cohesion (ClC,2007). However, the Department has taken no action to provide any practical guidance and resources to assist those carrying out such projects. Toolkits similar to those produced by the Home Office provide useful examples. At the very least, it would help practitioners if the respective government departments leading on the PSAs referred to earlier provided a link on their website to the CIP. 


\section{Future intergenerational Programmes and research}

Moore and Statham (2006) have written about the potential for intergenerational programmes being used to tackle the antisocial behaviour of young people and the perceived fear of crime experienced by some adults. However, they argue that there are various issues that need to be addressed. For example, the age range of younger generations used in research to date is too broad (0-25 years), while 'older generation' refers to adults over the age of 55 . This view is echoed by Springate et al $(2008, \mathrm{p} 18)$ who make the point that 'more work around the conceptual development of what intergenerational practice is and how it is defined' is needed. Epstein and Boisvert (2006, p 89), specifically referring to older adults, observe that some programme designs 'fail to acknowledge that elders are not homogenous'; one must not assume that a project that attracts 55 -year-olds is going to appeal, for example, to 65-yearolds.

Bernard (2006) stresses the need to look critically at the work done so far in order to develop the field of research and practice in a constructive and effective way. Similar to Fox and Giles (1993), she also emphasises the importance of addressing methodological issues. Viewing intergenerational relationships as a complex area, she argues strongly that both quantitative and qualitative approaches to data collection and analysis should be utilised. In addition, Seefeldt (1989) and Bernard (2006) argue the case for carrying out longitudinal studies; this could be achieved by drawing on existing datasets and combining them with new data. In relation to methodological development, Bernard $(2006, \mathrm{p} 17)$ raises the need for greater involvement of project participants in the research process at all stages of 'planning, doing, writing and dissemination'.

Pettigrew (2008) has outlined the future direction that research needs to follow if progress on refining intergroup contact theory is to be made. These points relate to intergenerational contact just as much as to other intergroup contact. Pettigrew (2008, p1) argues, for example, that:

There is a continuing need to specify the processes of intergroup contact that explain its many effects. This is a call for continued efforts to determine the many mediators and moderators that are involved....[M]ore direct applications to which intergroup contact is viewed within specific institutional settings.

While research into some aspects of intergenerational practice has been undertaken, a number of academics and practitioners working in this field have expressed the view that more work needs to be done to facilitate effective programme development. A major concern is the need to test out current theories and explore the building of new ones (Bernard, 2006). Kuehne (2003a, p157) suggests that there are many theories that can be 'applied to intergenerational programme development research and evaluation', and argues that, if this field is to flourish, the production of more, diverse literature needs to be generated based on theoretical research and programme evaluation. This, in turn, will generate 'better use of the theories and conceptual frameworks', which must be encouraged (Kuehne,2003b).

Given the different views on whether or not positive interpersonal contact between the generations has a beneficial impact on intergroup relations, more research is clearly needed in this area. Whether intergenerational programmes should necessarily seek to achieve positive intergroup attitude change is open to question. In some circumstances a change in interpersonal attitude may be all one can hope to achieve; this, in itself, can improve an individual's quality of life. Once interpersonal contact has been improved, then further contact programmes could be developed, building on the earlier programme, aimed at positive intergroup attitude change.

In order to inform future programmes it is important that an evaluation exercise is built into the design of projects and that findings are disseminated widely. It may be that evaluations are being carried out but not published (Granville, 2002). Although it is seven years since this point was made, it is still valid, and it is essential that both negative and positive findings are disseminated so that project leaders can avoid mistakes already made as well as emulate the successful features of projects. For example, anecdotal evidence suggests that projects can be less successful if an appropriate strategy is not developed to ensure the recruitment of appropriate participants. Project providers may find that the recruitment of suitable adults 
may be difficult in intergenerational projects aimed at bringing together teenagers and adults who perceive 'hanging around' to be a problem. Similarly, disaffected young people may not view 'working' with adults on a project as a very attractive proposition. In these circumstances it may be beneficial to build in activities where the different age groups initially work separately preparing them to work collaboratively later in the project. These recruitment challenges came to light in an evaluation carried out by the author of a community arts-based project between 2003 and 2006. In addition, there were difficulties in gaining the help of agencies not directly involved in the project to identify potential participants and be proactive in recruitment. Much could have been learnt by other practitioners about the potential pitfalls in recruitment and how to avoid them if the project funders had chosen to disseminate the evaluation findings. Dissemination of findings is not only important to ensure that future project design provides the participating individuals with the maximum benefit possible, but also to justify the funding of activities.

Currently there is a scarcity of UK community-based research to test theories that underpin projects or to develop conceptual frameworks. Raynes (2004) reiterates Kuehne's (2003a, 2003b) point that, while the UK can draw on research based in other countries, there is also a need for UK-based research. She does not suggest that research from other countries is valueless, rather that research is only valuable if its wider context is taken into account:

Whilst research from other countries...is of use, the particular circumstances and organisation of older people's services and children's services in England underline the need for nationally based research. The context and policy issues are different from those in the USA and...elsewhere in Europe. Knowledge generated in England can be shared with colleagues in practice, research and policy elsewhere to the mutual benefit of all concerned and the promotion of effective intergenerational practice. For this to be of wider value it will be important for those involved in intergenerational practice to better understand the policy contexts and service structures which exist.( Raynes,2004'pl9 a)

Bernard (2006) endorses this point, emphasising the importance both of disseminating research (and evaluation) findings more widely, and of including discussion on the cultural context within which research has been carried out. Given the multicultural nature of IJK society factors specific to individual cultural contexts may be relevant, for example, the influence of a specific religious or ethnic background. Culture-specific variables must be considered in intergenerational research in order to reduce the risk of misleading conclusions being drawn.

Of equal importance is the need to ensure that the writing up of findings is done in language that practitioners understand rather than in an inaccessible academic style. Greenwood and Levin (2008), referring to social research generally, criticise social scientists for tailoring their writing for an academic audience to the exclusion of others and:

Purposely engaging as little as possible in public debates and in issues that are socially salient. Often, their research is written up in language and with concepts that are incomprehensible to the people who are the 'subjects' of research and to those outside the university who might want to use the findings (Greenwood and Levin, 2008p, 58)

Given the UK government's advocacy of intergenerational projects, it is important that the points raised by Raynes (2004), Bernard (2006) and Greenwood and Levin (2008) receive attention so that practitioners responsible for designing and delivering intergenerational projects do so from an informed position'

\section{Conclusion}

The government has shown a welcome interest in intergenerational projects as a tool for improving community cohesion, tackling various social problems such as reducing adults' fear of 'teenagers hanging around', or improving young people's educational attainment or adults' self-esteem and self-worth. However, given the age of some publications cited in this article, more up-to-date and context-specific research and evaluation are clearly needed. The fact that information is starting to be disseminated is welcomed, but there is still a great deal to be 
done to ensure that successful, value-for-money projects are delivered and potential pitfalls avoided. Unless more guidance is made readily available, practitioners will be unaware of 'best practice' and risk repeating the mistakes of the past. In that case it is questionable whether intergenerational projects will in practice deliver the benefits hoped for by their proponents. A proportion of the funding being made available by the DCSF should be earmarked to ensure that evaluations and/or research-based exercises are made integral to projects. Equally important is facilitating the dissemination of research and evaluation in a more effective way in order to inform practitioners and facilitate work in this field.

\section{Notes}

${ }^{1}$ Centres for Intergenerational Practice - contact details: England - www.centreforip.org.uk Wales - www.glam.ac.uk/CCIP Northern Ireland - dsavage@ageconcernni.org

${ }^{2}$ The Respect Agenda is a UK government campaign to tackle antisocial behaviour; specifically focusing on young people and 'problem' families, and supporting them to change their behaviour (see www.respect.gov.uk).

${ }^{3}$ Age Concern is a UK national charity and Help the Aged is an international charity. Both work to improve the lives of older people.

${ }^{4}$ At the time of the search the DfES website was still accessible. It. Was superseded, in part, by the DCSF in June 2007 as part of a restructuring of government departments.

\section{References}

Abrams,J.andGiles,H. (1999) 'Intergenerational contact as intergroup communication', in V.S. Kuehn (ed) Intergenerational programs: Understanding what we have created, New York: Haworth.

Allport, G.W. (1954) The nature of prejudice, Cambridge, M A: Addison-Wesley.

Amir, Y. (1969) 'Contact hypothesis in ethnic relations', Psychological Bulletin, vol 71, no 5, pp 319-42.

Bernard, M (2006) 'Research policy, practice and theory: interrelated dimensions of a developing field', Journal of Intergenerational Relationships, v4, no 1, pp 5-22.

Berridge, T (2006) Together we can make it happen: An intergenerational approach, London: Age Concern, www.ageconcern.org.uk/AgeConcern/Documents/Intergen-booklet.pdf

Bocian, K. and Newman, S. (1989) 'Evaluation of intergenerational programs: why and how?', Journal of Children in Contemporary Society, vol 20, no 3/4, pp 147-63.

Caspi,A. (1984) 'Contact hypothesis and inter-age attitudes: a field study of cross-age contact', Social Psychology Quarterly, vol 47, no 1, pp 74-80.

Chapman, N.J. and Neal, M.B. (1990) 'The effects of intergenerational experiences on adolescents and older adults', The Gerontologist, vol 30, no 6, pp 825-32.

CIC (Commission on Integration and Cohesion) (2007) Our shared future, Wetherby: Department for Communities and Local Government Publications, http://image.guardian.co.uk/sysfiles,/Education/documents/2007/06/14/oursharedfuture.pdf

Dare, V (2008) Seminar presentation at Seminar 4: Intergenerational connections, 20 October, London: National Council for Voluntary Organisations, PowerPoint presentation available via http://democracy.carnegieuktrust.org.uk/node/322

Darlington District Council (undated) Intergenerational Project, webpage at www.darlington.gov. uk/Living/intergen.htm

DCLG (Department for Communities and Local Government) (2008) Public Service Agreements and departmental strategic objectives, London: DCLG, www.communities.gov.uk/corporate/about/howwework/publicserviceagreements/

DCSF (2009) '£5.5 million to help close the widening generation gap', Press Notice 2009/0076, www.dcsf.gov.uk/pns/DisplayPN.cgi?pn id=2009 0076

DfEE (Department for Education and Employment) (1998) Meeting the childcare challenge, London: DfEE, www.dcsf.gov.uk/everychildmatters/research/publications/surestartpublication/865

Edwards, H.and Giles, H.(1998) 'Prologue on two dimensions: the risk and management of intergenerational miscommunication', Journal of Applied Communication Research, vol 26, no 1, pp 1-12. 
Epstein, A. and Boisvert, C. (2006) 'Let's do something together: identifying the effective components of intergenerational programs', Journal of Intergenerational Relationships, vol 4, no 3, pp 87-109.

Fox, S. and Giles, H. (1993) 'Accommodating intergenerational contact: a critique and theoretical model', Journal of Aging Studies, vol 7, no 4, pp 423-51.

Furlong, A. and Cartmel, F. (1997) Young people and social change: Individualization and risk in late modernity, Buckingham: Open University Press.

Granville, G. (2002) A review of intergenerational practice in the UK, Stoke on Trent: Centre for Intergenerational Practice, www.centreforip.org.uk/default.aspx?page=23489

Granville, G. and Ellis, S.W. (1999) 'Developing theory into practice: researching intergenerational exchange', Education and Ageing, vol 14, no 3, pp 231-48.

Greenwood, D.J. and Levin, M. (2008) 'Reform of the social sciences and of universities through action research' in N.K. Denzin and Y.S. Lincoln (eds) The landscape of qualitative research, London: Sage Publications, pp 57-86.

Gudykunst, W.B. (2004) Bridging differences: Effective intergroup communication (4th edition), London: Sage Publications.

Hatton-Yeo, A. and Ohsako, T. (eds) (2000) Intergenerational programmes: Public policy and research implications - an international perspective, Paris: UNESCO Beth Johnson Foundation, www.centreforip.org.uk/Libraries/Local/949/Docs/UNESCO.pdf

Hewstone, M. (2003) 'Intergroup contact: panacea for prejudice?', Psychologist, vol 16, no 7 , pp 352-5-

Hewstone, M. and Brown, R. (1986) 'Contact is not enough: an intergroup perspective on the 'Contact Hypothesis', in M. Hewstone and R. Brown (eds) Contact and conflict in intergroup encounters, Oxford Blackwell, pp 1-44

HM Treasury (2008) 'Public Service Agreements: the new performance management framework', webpage at www.hm-treasury.gov'uk/pbr csr07 psaindex'htm

HM Treasury and DCSF (Department for Children, Schools and Families) (2007) Aiming high for young people: A ten year strategy for positive activities, London: HM Treasury, http://publications.dcsf.gov/uk/eOrderingDownload/PU214.pdf

HM Treasury and DCSF (2008) Aiming higher for young people: A ten year strategy for positive activities: Implementation plan, London: DCSF, www.dcsf.gov.uk/everychildmatters/Youth/aiminghigh/implementationplan/implement ationplan

Hobman, D. (ed) (1993) Uniting generations: Studies in confict and co-operation, London: ACE Books.

Ipsos Mori (2006) Young people and the media, London Ipsos Mori, www.ipsos-mori.com/ assets/polls/2005/pdf/young-people-now.pdf

Johnson, M. L. (1993) 'Generational relations under review', in D. Hobman (ed) Uniting generations: Studies in conflict and co-operation, London: ACE Books, pp 12-29

Kershaw, C., Nicholas, S.and Walker, A.(2008) Crime in England and Wales 2007/8: Findings from the British crime survey and police recorded crime, London: Home office, www.horne.office.gov.uk/rds/pdfs08/hosb0708.pdf

Kuehne, V.S. (2003a) 'The state of our art: intergenerational program research and evaluation: part one', Journal of Intergenerational Relationships, vol 1, no 1, pp 14561.

Kuehne, V.S. (2003b) 'The state of our art: intergenerational program research and evaluation: part two', Journal of Intergenerational Relationships, vol 1, 'no 2, pp 7994.

Lancashire County Council (2004) 'The young and old celebrate "intergenerational" project", Press Release 179, www3.lancashire.gov.uk/corporate/news/press releases/2004/09/30/0005.asp

Margo,J., Dixon,M., Pearce, N. and Reed, H (2006) Freedom's orphans: Raising youth in a changing world, London: Institute for Public Policy Research

Mayes, I (1999) 'Open door: senior disservice. The readers' editor on ... disrespect for our elderly'. The Guardian 27 Noventber, p7

Moore, S. and Statham, E. (2006) 'Can intergenerational practice offer a way of limiting antisocial behaviour and fear of crime?' Howard Journal of Criminal Justice' vol 45, no 5, pp 468-84.

National Youth Agency (2008) Youth action and engagement: Building intergenerational relationships, Leicester: The National Youth Agency,

www.nya.org.uk/files/110951/FileName/yae.pdf 
Newman, S.(2000) 'The United States', in A. Hatton-Yeo and T.Ohsako (eds)

Intergenerational programmes: Public policy and research implications - an international perspective, Paris: UNESCO Beth Johnson Foundation, www.centreforip.org.uk/Libraries/Local/949/Docs/UNESCO.pdf

$\mathrm{Ng}, \mathrm{S} . \mathrm{H}$. (1998) 'Social psychology in an ageing world: ageism and intergenerational relations', Asian Journal of Social Psychology, vol 1, no I, pp 99-116

Pain, R. (2005) Intergenerational relations and practice in the development of sustainable communities, Durham: International Centre for Regional Regeneration and Development Studies, Durham University, www.communities.gov.uk/documents/corporate/pdf/intergenerationalrelations.pdf

Pain, R. H. (1997) 'Old age and ageism in urban research the case of fear of crime', International Journal of Urban and Regional Research, vol21, no 1, pp 117-28.

Pettigrew, T.F: (1986) 'The intergroup contact hypothesis reconsidered', in M. Hewstone and R., Brown (eds) Contact and conflict in intergroup encounters, Oxford: Blackwell, pp 169-95.

Pettigrew, T.F. (1997) 'Generalized intergroup contact effects on prejudice', Personality and Social Psychology Bulletin, vol 23, no 2, pp 173-85.

Pettigrew, T.F. (1998) 'Intergroup contact theory', Annual Review of Psychology, vol 49, pp 65-85.

Pettigrew,T.F. (2008) 'Future directions for intergroup contact theory and research' International Journal of Intercultural Relations, vol 32, no 3, pp 187-99

Pinquart, M., Wenzel, S. and Sorensen, S. (2000) 'Changes in attitudes among children and elderly adults in intergenerational group work', Educational Gerontology, vol 26, no 6, pp 523-40.

Raynes, N. (2004) 'Where are we now with intergenerational practice: an English perspective', International Journal of Intergenerational Relationships vol 2, no 3/4, pp 187-95.

Respect Task Force (2006) Respect action plan, London: Home Office, www.homeoffice.gov.uk/documents/respect-action-plan

Rogers, R.S. (2004) 'The making and moulding of modern youth: a short history', in J.Roche, S.Tucker, R.Thomson and R. Flynn (eds) Youth in society ( $2^{\text {nd }}$ edition), London: Sage Publications.

Rosenbaum, W.A. and Button, J.W. (1992) 'Perceptions of intergenerational conflict: the politics of young vs old in Florida', Journal of Aging Studies, vol 6, no 4, pp 385-96.

Seefeldt, C. (1989) 'Intergenerational programs impact on attitudes', Journal of children in Contemporary Society, vol 20, no 3/4, pp 147-63.

Silverstein, M., Parrott, T. M., Angelelli, J.J. and Cook, E.L. (2000) 'Solidarity and tension between age-groups in the United States: challenge for an aging American in the 21st century', International Journal of Social Welfare, vol 9, no 4, pp 270 -84.

Soliz, J. and Harwood, J. (2003) 'Perceptions of communication in a family relationship and the reduction of intergroup prejudice', Journal of Applied Communication Research, vol 31, no 4, PP 320-45.

Springate, I., Atkinson, M. and Martin, K. (2008) Intergenerational practice: A review of the literature, LGA Research Report F/SR262, Slough: National Foundation for Educational Research, www.nfer.ac.uk/research-areas/pimsdata/summaries/intergenerational-practice-literature-review.cfrn

St James-Roberts, I. and Singh, C.S. (2001) Can mentors help primary school children with behaviour problems?, Home Office Research Study 233, London: Home Office, www.homeoffice.gov.uk/rds/pdfs/hors233.pdf

Tinker, A. (1993) 'Housing', in D. Hobman (ed) Uniting generations: Studies in conflict and cooperation, London: Age Concern England.

Walker, A.(1993) 'Whither the social contract? I ntergenerational solidarity in income and employment', in D. Hobman (ed) Uniting generations: Studies in conflict and cooperation, London: Age Concern England.

West Lindsey District Council (2004) Gainsborough Intergenerational Community Safety Project, Report to the Community Services Committee, Gainsborough West Lindsey District Council, http://committee.westlindsey.gov.uk/comm mins/documents/archive/Comm/Reports/Comm0110R.htm

Wyn, J. and White, R. (1997) Rethinking youth, London: Sage Publications. 